\title{
STUDENT'S CARDIOVASCULAR HEALTH AWARENESS DURING COVID-19 PANDEMIC PROCESS: THE CASE OF SIVAS, TURKEY
}

\author{
Erkan Konca ${ }^{1 i}$, \\ Egemen Ermiş², \\ Necati Alp Erilli ${ }^{3}$, \\ Aydan Ermiş ${ }^{4}$ \\ ${ }^{1}$ Yavuz Selim Secondary School, \\ Sivas, Turkey \\ ${ }^{2}$ Yaşar Doğu Faculty of Sport Sciences, \\ Department of Coaching Training, \\ Ondokuz Mayıs University, \\ Samsun, Turkey \\ ${ }^{3}$ Faculty of Economics, \\ Department of Econometrics, \\ Sivas Cumhuriyet University, \\ Sivas, Turkey \\ 4School of Foreign Languages, \\ Ondokuz Mayıs University, \\ Samsun, Turkey
}

\begin{abstract}
:
Cardiovascular diseases, one of the important health problems of our day, seriously threaten human health. For this reason, it is very important to raise awareness about cardiovascular health from childhood and to develop behaviors accordingly. The aim of this study is to find out cardiovascular health awareness in students between the ages of 7 and 16 during the pandemic. 216 students continuing their education in the city centre of Sivas, Turkey participated in the study. A survey form on socio-demographic characteristics of the students and Children's Cardiovascular Health Promotion Attitude Scale (CCHPAS) were used in the study. Demographic characteristics were collected online with a 9-question form. KMO value (0.741) was found to be moderate. Bartlett Sphericity test $(p=0.00)$ was found to be significant. The fact that these two values are significant shows that the survey is suitable for factor analysis. 4 factors were determined as a result of factor analysis. These 4 factors explain $60 \%$ of the variance. No statistically significant difference was found in both total scale and 4 factors in terms of gender $(p>0.05)$. While no statistically significant difference was found for the first factor in terms
\end{abstract}

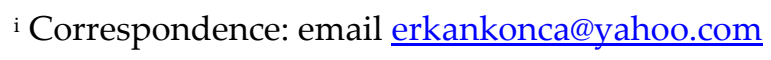


of the state of having social media account ( $p>0.05)$, significant difference was found for the other factors and total scale score $(p<0.05)$. It was also examined whether there were differences between factors and total scale score in terms of age groups, and while no statistically significant difference was found in terms of Factor 1, Factor 2 and Factor 4 $(p>0.05)$, difference was found in terms of Factor 3 and total scale scores $(p<0.05)$. As a result of the study, it was found that the participants had good level of awareness about cardiovascular health.

Keywords: children's cardiovascular health, nutrition, stress, exercise, smoking

\section{Introduction}

In recent years, one of the most important problems threatening our health has been cardiovascular diseases. The cardiovascular system consists of heart and vasculars in human body. The oxygen uptake is very important in terms of exercise performance (Ari et al., 2017). Therefore, cardiovascular system provides oxygen to body tissues and muscles. However, a sedentary lifestyle, unhealthy eating habits, cigarette and alcohol consumption pave the way for cardiovascular diseases. Raising awareness about cardiovascular diseases starting from childhood is very important in terms of preventing cardiovascular diseases that may occur in the future. According to World Health Organization statistics, cardiovascular diseases (CVD), which rank the first among the causes of death in the world, constitute $30 \%$ of all deaths; while this rate is $47 \%$ in Turkey (Ministry of Health, 2010; World Health Organization, 2003).

While age, gender, family history and ethnic origin are unchangeable risk factors for cardiovascular diseases, smoking, insufficient physical activity, diabetes, obesity, hypertension, dyslipidaemia and stressful life style are changeable risk factors (Ebrahim and Smith, 2001; Metin et al., 1998; Rakel, 1990; SB, 2010; Wimbush and Peters, 2000). The physical activity includes main performance components such as strength, endurance, speed, stretching, power and agility (Baynaz et al., 2017; Ari and Deliceoglu, 2020; Sajedi et al., 2020). These components may be developed by regular physical activity. Also, regular physical activity may create important differences in the healthy upbringing and development of children and adolescents, in getting rid of unwanted bad habits, in socializing, in the protection of adults from various chronic diseases or in the treatment of these diseases or in supporting treatment, in ensuring that elderly people have an active old age period; in other words, in improving the quality of life in all stages of life (Baltac1, 2008). School environment, which is effective in children's acquiring behaviors, is suitable for teaching health promoting behaviors to children (Baylor, 2009; Pelitoğlu and Özgür, 2013). Students' perceiving healthy lifestyle behaviors and applying these in their lives will also improve social health in addition to providing a healthy life perspective to students (Özkan, 2020). For this reason, health promoting schools may influence children's cardiovascular attitudes (Y1ld1z et al., 2016). A large number of studies conducted on adults have stated that especially risk factors in coronary diseases 
go back to childhood. In a study conducted on 12-15 years age group in Northern Ireland, it was found that $15-23 \%$ of the participants had unrecorded increased blood pressure, $12-25 \%$ had an undesired lipid profile and $18-34 \%$ had excessive fat. In another study, it was emphasized that $69 \%$ of the children older than 12 years of age had at least one coronary artery disease-related modifiable risk factor. It was also reported that approximately $13 \%$ of children and adolescents had undesired blood fat and lipoprotein profile and they were classified as overweight (Baltac1, 2008). In a study by Koca and Fazlıogulları, it was recommended to increase activity period considering the effects of decreased physical activity periods on public health. They stated that in the ongoing process, home-based activities were the most important opportunity for people to stay fit and healthy. In a study conducted in the Czech Republic, it was found that pandemic restrictions had a negative effect on children's physical activity levels (Stverakov et al., 2021).

Smoking comes to the fore in studies conducted recently on the negative effects of harmful habits on humans (Bostanci et al., 2019). It is estimated that in the USA, annually 62000 people die of heart diseases due to second-hand smoke exposure (Mackay \& Eriksen, 2001). Smoking in environments with children threatens children's health and it also violates both human rights and also children's rights. The most successful way of getting rid of harmful effects is creating smoke-free environments. This advocacy for children should be carried out by children themselves through role models such as healthcare professionals, teachers and parents and also through increasing levels of awareness. One of the three steps of fighting smoking is preventing environmental tobacco smoke exposure and studies should be carried out with this perspective (Hopkins et al., 2001). Other steps (preventing initiation of smoking and quitting smoking) also have a very important place in this fight. The increase in social media use and the time spent with media tools also may cause negations on children. Numerous negative effects have emerged due to the uncontrolled and unlimited use of television and other media tools, which can ne very useful when used correctly and in a controlled way (Baron , 2000). Children of our day have started playing games without talking for hours and making eye contact by sitting in front of the computer when they get together and therefore, the incidence of obesity has increased (Villani, 2001; Bilgiç et al., 2011). Children sit for a long time in front of the TV instead of running and playing. They consume high energy snacks advertised in commercials instead of fruit and vegetable, which have lower energy. Therefore, watching television both increases the consumption of high level energy food consumption and also decreases physical activity and obesity develops as a result (American Academy of Pediatrics, 1999; Bostanc1 et al., 2019). There are exaggerated visual messages in the media that the use of cigarettes, alcohol and illegal drugs is normal and these are increasing gradually. In America, cigarette manufacturers spend 6 billion dollars each year, while alcohol manufacturers spend 2 billion dollars to make young people use these. In popular movies, protagonists are frequently seen to use cigarette and alcohol (Baron, 2000). 
In an environment in which cardiovascular diseases are a serious threat, Covid-19 pandemic which started to affect the whole world starting from late 2019 brought along may psychological and sociological problems such as insufficient physical activity, unhealthy nutritional habits and increased stress levels (Mayda et al., 2020; Acar et al., 2020). In a study conducted by Korkmaz et al. on 269 secondary education students during the pandemic process, $65 \%$ of the participants stated that their physical activity levels decreased during Covid-19 pandemic and it was found as a result of the analyses that the time spent with exercise was significantly different during normal times and during Covid-19 pandemic ( $\mathrm{p}<0.05)$ and significant decrease occurred in time spent with exercise during Covid-19 pandemic. It was found that $17.2 \%$ of the students during Covid-19 pandemic and 18,1\% during normal times showed the recommended weekly physical activity. In a study conducted in Italy with 2524 participants during the pandemic process, it was reported that physical activity decreased when compared with pre Covid-19 period (Maugeri et al., 2020). It was shown that during the Covid-19 pandemic, physical inactivity rates of university students increased at an alarming rate and students who were decisive to maintain their regular physical activity behaviors changed their activity styles and adapted to the process (Ercan and Keklicek, 2020). It was shown that physical activity levels decreased as a result of obeying social isolation rules and the time spent sitting increased (Wernecka et al., 2019). It may be possible to prevent an important health problem such as cardiac health with correct behaviours to be gained from an early age. The fact that face-to-face education in schools was replaced with distance education during the pandemic period led to students' continuing their active lives in front of computer screens. A research was planned to find out the awareness of children about physical activity, diet and cardiac health during this process. In our study, Children's Cardiovascular Health Promotion Attitude Scale (CCHPAS), the reliability and validity study of which was conducted by Öztürk M. and Bahar Z., was applied to students between the ages of 7 and 16 who were living and studying in the province of Sivas during the Covid 19 pandemic. $9.3 \%$ of the students who filled in the surveys were 7-8 years old, $14,4 \%$ were $9-10$ years old, $43,1 \%$ were $11-12$ years old, $21.3 \%$ were $13-14$ years old and $12 \%$ were $15-16$ years old. $19.9 \%$ of the students were attending primary education, while $64.8 \%$ were attending secondary education and $15.3 \%$ were attending high school education.

\section{Material and Method}

\subsection{Sample of the Study}

Schools were selected from 3 different regions to find out the differences in gender, socioeconomic level and health behaviors in the city centre of Sivas province in Turkey. The majority of the sample consisted of secondary education students. 216 students participated in the study. 


\subsection{Data Collection Tools}

A questionnaire form to determine the socio-demographic characteristics of the students and Children's Cardiovascular Health Promotion Attitude Scale (CCHPAS) were used in the study. Socio-demographic characteristics were collected online with a form consisting of 9 questions.

\subsection{Statistical Analyzes}

Statistical analyzes of the study were made with SPSS.22 package program. Confidence level was taken as 0.05 in all methods used in the study. In the study, Factor Analysis was used to evaluate the questionnaire questions, correlation analysis was used to determine the relationships between the factors, t-test was used for the comparison of 2 groups, and ANOVA methods were used for the comparison of the differences between the groups.

\section{Results}

As expected, the correlation between the factors was found to be low. The highest correlation was determined between Factor 1 and Factor 2 as a parallel and moderate correlation.

Table 1: Correlations between the factors

\begin{tabular}{|c|c|c|c|c|c|}
\hline & Factor 1 & Factor 2 & Factor 3 & Factor 4 \\
\hline & & (Exercise) & (Diet) & (Smoking) & (Stress management) \\
\hline \multirow{2}{*}{$\begin{array}{l}\text { Factor } 1 \\
\text { (Exercise) }\end{array}$} & $\mathrm{r}$ & \multirow[t]{2}{*}{$* * *$} & $.422^{* *}$ & $.186^{* *}$ & $.232^{* *}$ \\
\hline & $\mathrm{p}$ & & 0 & 0.006 & 0.001 \\
\hline \multirow{2}{*}{$\begin{array}{l}\text { Factor } 2 \\
\text { (Diet) }\end{array}$} & $\mathrm{r}$ & $.422^{* *}$ & \multirow[t]{2}{*}{$* * *$} & 0.125 & $.346^{* *}$ \\
\hline & $p$ & 0 & & 0.068 & 0 \\
\hline \multirow{2}{*}{$\begin{array}{l}\text { Factor } 3 \\
\text { (Smoking) }\end{array}$} & $\mathrm{r}$ & $.186^{* *}$ & 0.125 & \multirow[t]{2}{*}{$* * *$} & 0.086 \\
\hline & $\mathrm{p}$ & 0.006 & 0.068 & & 0.206 \\
\hline \multirow{2}{*}{$\begin{array}{l}\text { Factor } 4 \\
\text { (Stress management) }\end{array}$} & $\mathrm{r}$ & $.232^{* *}$ & $.346^{* *}$ & 0.086 & \multirow[t]{2}{*}{$* * *$} \\
\hline & $p$ & 0.001 & 0 & 0.206 & \\
\hline
\end{tabular}

KMO value (0.741) was found to be moderate. Bartlett Sphericity test $(p=0.00)$ was also found to be significant. These two values' being significant shows that the scale is suitable for Factor Analysis.

The 4 factors were determined as a result of factor analysis. These 4 factors explain $60 \%$ of the variance. The table below shows the factor loads of the items according to the factors they are in. 
Table 2: Factor loads of the items according to the factors they are included in

\begin{tabular}{|c|c|c|c|c|}
\hline \multirow{2}{*}{$\begin{array}{l}\text { S/n } \\
\text { o }\end{array}$} & Factor 1 & Factor 2 & Factor 3 & Factor 4 \\
\hline & (Exercise) & (Diet) & (Smoking) & (Stress management) \\
\hline 1 & 0.76 & & & \\
\hline 2 & 0.781 & & & \\
\hline 3 & 0.808 & & & \\
\hline 4 & 0.803 & & & \\
\hline 5 & & 0.636 & & \\
\hline 6 & & 0.822 & & \\
\hline 7 & & 0.758 & & \\
\hline 8 & & 0.477 & & \\
\hline 9 & & & 0.887 & \\
\hline 10 & & & 0.734 & \\
\hline 11 & & & 0.891 & \\
\hline 12 & & & 0.575 & \\
\hline 13 & & & & 0.824 \\
\hline 14 & & & & 0.874 \\
\hline 15 & & & & 0.683 \\
\hline 16 & & & & 0.276 \\
\hline
\end{tabular}

The results found as a result of factor analysis were the same with the results obtained in validity and reliability study conducted by Öztürk and Bahar.

Table 3: Correlation between factors and gender

\begin{tabular}{|l|l|c|c|c|}
\hline \multicolumn{2}{|c|}{} & Mean & Std. Dev. & p \\
\hline Factor 1 & Female & 6.36 & 2.63 & 0.126 \\
\cline { 2 - 4 } (Exercise) & Male & 6.89 & 2.40 & \\
\hline \multirow{2}{*}{$\begin{array}{l}\text { Factor } 2 \\
\text { (Diet) }\end{array}$} & Female & 7.98 & 2.99 & \multirow{2}{*}{0.607} \\
\cline { 2 - 5 } $\begin{array}{l}\text { Factor 3 } \\
\text { (Smoking) }\end{array}$ & Male & 7.79 & 2.49 & \\
\hline Factor 4 & Female & 8.68 & 1.95 & 0.245 \\
\cline { 2 - 5 } (Stress management) & Male & 8.40 & 1.42 & \\
\hline Total Scale & Female & 6.43 & 2.32 & 0.34 \\
\cline { 2 - 5 } & Male & 6.76 & 2.71 & \multirow{2}{*}{0.646} \\
\hline
\end{tabular}

No statistically significant difference was found in both total scale score and 4 factors in terms of gender $(\mathrm{p}>0.05)$. 
Erkan Konca, Egemen Ermiş, Necati Alp Erilli, Aydan Ermiş STUDENT'S CARDIOVASCULAR HEALTH AWARENESS DURING COVID-19 PANDEMIC PROCESS: THE CASE OF SIVAS, TURKEY

Table 4: Correlations between factors and the state of having social media

\begin{tabular}{|l|l|c|c|c|}
\hline \multicolumn{2}{|c|}{} & Mean & Std. Dev. & p \\
\hline \multirow{2}{*}{$\begin{array}{l}\text { Factor } 1 \\
\text { (Exercise) }\end{array}$} & Students with social media & 6.46 & 2.50 & \multirow{2}{*}{0.543} \\
\cline { 2 - 4 } $\begin{array}{l}\text { Factor } 2 \\
\text { (Diet) }\end{array}$ & Students with no social media & 6.67 & 2.59 & \\
\hline \multirow{2}{*}{$\begin{array}{l}\text { Factor 3 } \\
\text { (Smoking) }\end{array}$} & Students with social media & 8.56 & 3.20 & \multirow{2}{*}{$0.002^{*}$} \\
\cline { 2 - 4 } $\begin{array}{l}\text { Factor 4 } \\
\text { (Stress management) }\end{array}$ & Students with no social media & 7.39 & 2.31 & \\
\cline { 2 - 4 } Students with social media & 8.84 & 1.92 & \multirow{2}{*}{$0.041^{*}$} \\
\cline { 2 - 4 } Total Scale & Students with no social media & 8.35 & 1.58 & \\
\cline { 2 - 4 } & Students with social media & 7.04 & 2.90 & \multirow{2}{*}{$0.016^{*}$} \\
\cline { 2 - 4 } & Students with no social media & 6.21 & 2.07 & \\
\cline { 2 - 4 } & Students with social media & 30.92 & 6.59 & \multirow{2}{*}{$0.010^{*}$} \\
\cline { 2 - 4 } & Students with no social media & 28.65 & 6.09 & \\
\hline
\end{tabular}

While no statistically significant difference was found for the first factor in terms of the students' states of having social media $(p>0.05)$, difference was found for other factors and total scale score $(\mathrm{p}<0.05)$.

It was also examined whether there were differences between students' age groups in terms of factors and total scale scores and while no statistical difference was found in terms of Factor 1, Factor 2 and Factor 4 ( $p>0.05)$, difference was found in terms of Factor 3 and total scale scores $(\mathrm{p}<0.05)$. The difference in Factor 3 was found to be between 9-10 age group and 15-16 age group. Similarly, the difference between total scale scores was found to be between 9-10 age group and 15-16 age group in total scale scores. It was examined whether there were differences between students' school categories in terms of factors and total scale scores and statistically significant difference was found in all groups ( $p>0.05$ ). The difference in Factor 1 was found to be between secondary school and high school, the difference in Factor 2 was found to be between primary school and high school, the difference in Factor 3 was found to be between secondary school and high school, between primary school and high school and between secondary school and high school in terms of total scale scores. No statistically significant difference was found between family income level in terms of factors and total scale scores $(p>0.05)$. No statistically significant difference was found between students' computer use time in terms of factors and total scale scores $(\mathrm{p}>0.05)$. Similarly, no statistically significant difference was found between parental educational states of students in terms of factors and total scale scores $(\mathrm{p}>0.05)$. No statistically significant difference was found between students' daily social media use times ( $p>0.05)$, while statistically significant difference was found between Factor 1 and Factor $(\mathrm{p}<0.05)$.

\section{Discussion and Conclusion}

One of the most important problems caused by Covid 19 virus, which has affected the whole world, is the change in routine behaviours or the abandonment of these behaviours. Quarantine practices have limited the movement areas of individuals and led them to a sedentary life style. The most important measure in reducing the risk in 
epidemics is social isolation and home quarantine (Barazoni et al., 2020). Since these isolations may cause a more sedentary lifestyle and eating disorders, it may be thought that they may have long-term effects in terms of cardiovascular diseases in the future. For this reason, potential benefits of quarantine practices and long-term negative effects of cardiovascular diseases should be well compared (Mattioli et al., 2020). It is very important to comply with healthy eating principles during quarantine periods and normal periods (Kartal et al., 2020). It has become extremely important to teach regular physical activity habits from young ages and to enable students to have the motivation, knowledge and skills to perform physical activities on individuals' own (Korkmaz et al., 2020). Pandemic period has been very effective on children, who normally have a very active life. The aim of our study is to examine the awareness levels of children exposed to this effect on cardiovascular health.

Children's Cardiovascular Health Promotion Attitude Scale (CCHPAS), the reliability and validity study of which was conducted by Öztürk and Bahar, was applied to students living in Sivas. 216 students participated in the survey, $57.9 \%$ of these students were female and $42.1 \%$ were male. $9.3 \%$ of the participants were between $7-8$ years of age, $14.4 \%$ were between $9-10$ years of age, $43.1 \%$ were between $11-12$ years of age, $21.3 \%$ were between $13-14$ years of age and 12\% were between 15-16 age group. In terms of educational status, $19,9 \%$ were in primary education, $64.8 \%$ were in secondary education and $15.3 \%$ were in high school education. When maternal educational states were examined, it was found that $34.3 \%$ of the students were high school graduates and $23.1 \%$ were university graduates. In terms of paternal educational states, it was found that $40.3 \%$ were high school graduates and $29.6 \%$ were university graduates. In terms of family income level, it was found that $30.6 \%$ had very low level of income, while $25 \%$ had low level of income and $21.3 \%$ had moderate level of income.

In terms of daily computer use rates, it was found that $23.6 \%$ of the students spent 2 hours a day in front of the computer, followed by $19.4 \%$ of the students spending more than 5 hours. It can be said that courses being online during the pandemic process may be one of the main reasons for the excessive time spent in front of the computer. When the time spent in social media was examined, it was found that $41.2 \%$ of the students did not spent time in the social media, while $21.8 \%$ of the students spent 1 hour a day in the social media.

Children's Cardiovascular Health Promotion Attitude Scale includes the factors of exercise, diet, smoking and stress management. It was found that the participants had high awareness in all factors.

While no statistically significant difference was found in exercise, diet and stress management factors in all age groups, difference was found between 9-10 and 13-14 age groups and 15-16 age group in terms of smoking. This difference can be interpreted as students in 9-10 age group being more sensitive to students in 13-16 age group. Statistically significant differences were found between total scale scores and factors of primary, secondary and high school education students. It can be said that the perspectives of students about the factors in the scale differ when school levels differ. 
Family income level, computer use times and family educational status do not have any statistical effect on factors and total scale scores. In the validity and reliability study conducted by Öztürk M. and Bahar Z., when educational status of parents were evaluated, it was found that $46.1 \%$ were primary education graduates, $16.1 \%$ were secondary education graduates, 30.9\% were high school graduates, $7 \%$ were college graduates and there were no statistically significant differences between diagnosis groups in terms of parental educational status $(p>0.05)$. When the mean ages and employment status of the parents who participated in a study by Memik, N. et al. were evaluated, no difference was found between diagnosis groups (Memik et al., 2007).

While daily social media use times of the students were not found to differ statistically in terms of exercise and smoking factors, they were found to differ statistically significantly in terms of diet and stress management. This result can be interpreted as the fact that eating disorders and unhealthy eating habits may occur in children under stress. Social media use can be said to be effective on diet and social life. While the correlations between factors were found to be low as expected, a parallel and moderate correlation was found between the factors of exercise and diet. It was found that the results in the validity and reliability study of the scale were similar to the results found in the study conducted during the pandemic process. This result can be interpreted as the pandemic process not creating difference on cardiovascular health attitudes of students.

\section{Recommendations}

In line with the results found in the study, it can be recommended to provide information about cardiovascular health in curricula of schools to raise awareness starting from young ages.

It is also recommended to carry out studies to ensure that physical activity is an indispensable part of daily life starting from young ages and to raise awareness about the negative effects of unhealthy dietary elements, which is one of the greatest issues of our day.

Recommendations can also be made to relevant ministries to prepare and implement an action plan to identify the long term effects of exercise, diet, harmful effects and socio-economic dimensions of cardiovascular health in school age children.

\section{Conflict of Interest Statement}

The authors declare no conflicts of interests.

\section{About the Authors}

Dr. Erkan Konca has a Doctor's degree in the sport science field.

Dr. Egemen Ermiş is Associate Professor Doctor at Ondokuz Mayıs University, Yaşar Doğu Faculty of Sports Sciences, Samsun, Turkey. 
Dr. Necati Alp Erilli is Associate Professor Doctor at Sivas Cumhuriyet University, Faculty of Economics Department of Econometrics, Statistical Department, Sivas, Turkey. Dr. Aydan Ermiş, School of Foreign Languages, Ondokuz Mayıs University, Samsun, Turkey.

\section{References}

Acar, K., Mor, A., Baynaz, K., Arslanoğlu, E. (2020). An investigation on anxiety states of students in faculty of sport sciences during COVID-19. International Journal of Disabilities Sports and Health Sciences, 3(1), 66-73.

American Academy of Pediatrics (1999). Committee on Public Education. Media education. 104/2, s. 341. Pediatrics.

Ari, E., Cihan, H., Can, İ., Demir, B. (2017). The Compare of Oxygen Uptake Kinetics of Young Soccer Players According to Play Positions. The Journal of International Anatolia Sport Science, 2(1), 102-112.

Ari, E., Deliceoglu, G. (2020). The Examination of Some Anthropometric and Motoric Characteristics of Students Aged Eight Years According to Their Maturation Level. Baltic Journal of Health and Physical Activity, 12(2), 45-63.

Baltacı, G. (2008). Children and Sports. Ankara: Sağlık Bakanlığı.

Barazzoni, R., Bischoff, S., Krznaric, Z., Pirlich, M., \& Singer, P. (2020). Expert Statements and Practical Guidance for Nutritional Management of Individuals With SARSCoV-2. Clinical Nutrition, 4(20), 301-400.

Baron, M. (2000). The Effects of Television on Child Health: Implications and Recommendations. Arch Dis Child(83), 289.

Baylor, S. (2009). Promoting community health nursing education through an elementary school health fair. NASN School Nurse.

Baynaz, K., Acar, K., Çinibulak, E., Atasoy, T., Mor, A., Pehlivan, B., \& Arslanoğlu, E. (2017). The effect of high intensity interval training on flexibility and anaerobic power. Journal of Human Sciences, 14(4), 4088-4096.

Bilgiç, M., Sağlik, M., Türk, H., Yayla, R. (2011). Evaluation of some physical performance characteristics of children with and without regular football activities for 6 months. 4th International Sports Sciences Student Congress.

Bostanc1, Ö., Kabadayı, M., Mayda, M. H., Yılmaz, A. K., \& Yılmaz, C. (2019). The differential impact of several types of sports on pulmonary functions and respiratory muscle strength in boys aged 8-12. Isokinetics and Exercise Science, 27(4), 307-312.

Bostanci, Ö., Mayda, H., Yılmaz, C., Kabadayı, M., Yılmaz, A. K., \& Özdal, M. (2019). Inspiratory muscle training improves pulmonary functions and respiratory muscle strength in healthy male smokers. Respiratory physiology \& neurobiology, 264, 28-32. 
Ebrahim, S., \& Smith, G. (2001). Exporting Failure: Coronary Heart Disease and Stroke in Developing Countries. International Journal of Epidemiology(30), 201-205.

Ercan, Ş., \& Keklicek, H. (2020). An Investigation of Changes in Physical Activity Levels of University Students Due to the COVID-19 Pandemic. Journal of Izmir Katip Celebi University Faculty of Health Sciences, 5(2), 69-74.

Haney Öztürk, M., \& Bahar, Z. (2014). Validity and Reliability of the Child Heart Health Promotion Attitude Scale. DEUHYO ED, 2(7), 92-97.

Hopkins, D., Briss, P., \& Richard, C. (2001). Reviews of Evidence Regarding Interventions to Reduce Tobacco Use and Exposure to Environmental Tobacco Smoke. AMJ Prev Medicine, 2S(20).

Kartal, A., Ergin, E., \& Kanmış, H. (2020). Healthy Diet and Physical Activity Recommendations to Improve Quality of Life during the COVID-19 Pandemic Epidemic Period. Eurasian Journal of Health Sciences(3), 149-155.

Koca, R., \& Fazlıoğulları, Z. (2021). Investigation of the Effect of the Covid 19 Pandemic Process on the Physical Activity Periods of Young People. Journal of General Medicine, 2(31), 153-158.

Korkmaz, H., Öztürk, İ., Rodoslu, C., \& Uğur , S. (2020). Investigation of Changes in Physical Activity Levels of Secondary School Students during the Covid-19 Epidemic (Bursa Province Example). Atatürk University Journal of Physical Education and Sport Sciences, 22(4).

Mackay, J., \& Eriksen, M. (2001). Passive Smoking. Tobacco Atlas.

Mattioli, A., \& Ballerini Puviani, M. (2020). Lifestyle at Time of COVID-19: How Could Quarantine Affect Cardiovascular Risk. American Journal of Lifestyle Medicine, 3(14), 240-242.

Maugeri, G., Castrogiovanni, P., Battaglia, G., Pippi, R., D’Agata, V., \& Palma, A. (2020). The Impact of Physical Activity on Psychological Health During Covid-19 Pandemic in Italy. Heliyon, 6(6).

Mayda, M. H., Erail, S., \& Karaduman, E. (2020). Examination Of Self-Regulated Online Learning Skills In Faculty Of Sports Sciences Students. European Journal of Education Studies, 7(11).

Memik, N., Ağaoğlu, B., Coşkun, A., Üneri, Ö., \& Karakaya, I. (2007). Validity and Reliability of the 13-18 Age Adolescent Form of the Child Quality of Life Scale. Turkish Journal of Psychiatry, 18(4), 353-363.

Metin, B., Akın, A., \& Güngör, I. (1998). WHO Health Report Life in the 21st Century A Vision for All. Ankara: Ministry of Health Health Project General Coordinatorship.Organization, W. H. (2003). Report of the World Health Organization Study Group Diet Nutrition and the Prevention of Chronic Diseases. WHO.

Özkan, A. (2020). Investigation of Physical Activity Level and Healthy Lifestyle Behaviors of Health Services Vocational School Students. International Journal of Contemporary Educational Research, 1(6), 112-126. 
Pelitoğlu, F., \& Özgür, S. (2013). Developing a Health Attitude Scale for Primary School Students. Necatibey Faculty of Education Journal of Electronic Science and Mathematics Education, 1(7).

Rakel, R. (1990). Textbook of Family Practice. Philadelphia: Philadelphia.

Sağlık Bakanlığı (2010). Turkey Cardiovascular Diseases Prevention and Control Program. Strategic Plan and Action Plan for Primary Secondary, Tertiary Protection. Ankara: T.C. Ministry of Health.

Sajedi, H., Bayram, M., \& Bilgiç, M. (2020). Effect of PNF, Ballistic and Static Stretching on the Range of Motion after Sports Injury Surgery in Football Athletes. African Educational Research Journal, 8(1), 105-109.

Stverakova, T., Jacisko, A., Safarova, M., Kolar , P., \& Kobesova, A. (2021). The Impact of Covid-19 on Physical Activity of Czech Children. Plos One, 16(1).

Villani, S. (2001). Impact of Media on Children and Adolescents: a 10 Year Review of the Research. Jam Acad Child Adolesc Psyhiatry, 2(40), 392-401.

Wernecka, A., Collingsb, P., Stubbse, B., \& Silvac, D. (2019). Associations of sedentary behaviors and physical activity with social isolation in 100,839 school students: The Brazilian Scholar Health Survey. Journal of General Hospital Psychiatry, 59(7).

Wimbush, F., \& Peters, R. (2000). Identification of Cardiovascular Risk. Public Health Nursing, 3(17), 148-154.

Yıldız, E., Albayrak, E., Öztürk, S., \& Kılıç, M. (2016). Turkey Cardiovascular Diseases Prevention and Control Program. Strategic Plan and Action Plan for Primary Secondary, Tertiary Protection. Ankara: T.C. Ministry of Health. 1st International Congress of Women and Child Health and Education, (s. 66-80). 
Erkan Konca, Egemen Ermiş, Necati Alp Erilli, Aydan Ermiş

Creative Commons licensing terms

Authors will retain the copyright of their published articles agreeing that a Creative Commons Attribution 4.0 International License (CC BY 4.0) terms will be applied to their work. Under the terms of this license, no permission is required from the author(s) or publisher for members of the community to copy, distribute, transmit or adapt the article content, providing a proper, prominent and unambiguous attribution to the authors in a manner that makes clear that the materials are being reused under permission of a Creative Commons License. Views, opinions and conclusions expressed in this research article are views, opinions and conclusions of the author(s). Open Access Publishing Group and European Journal of Physical Education and Sport Science shall not be responsible or answerable for any loss, damage or liability caused in relation to/arising out of conflict of interests, copyright violations and inappropriate or inaccurate use of any kind content related or integrated on the research work. All the published works are meeting the Open Access Publishing requirements and can be freely accessed, shared, modified, distributed and used in educational, commercial and non-commercial purposes under a Creative Commons attribution 4.0 International License (CC BY 4.0). 